\title{
Modeling Method of Heat Transfer During Vapour Phase Soldering Based on Filmwise Condensation Theory
}

\author{
Attila Géczy, Balázs Illés, and Zsolt Illyefalvi-Vitéz \\ Budapest University of Technology and Economics, \\ Department of Electronics Technology, \\ Budapest, Egry J. u. 18., V1 Building, V1-013, H-1111 \\ Email: gattila@ett.bme.hu; Tel:+36-30-463 2755; Fax: +36-1-463-4118
}

\begin{abstract}
The paper presents a practical method for calculating the heat transfer during Vapour Phase Soldering (VPS) process. VPS is a reflow soldering method based on condensation heating and used in the electronics manufacturing. The presented explicit model describes solutions for filmwise condensation heat transfer based on the Nusselt theory. Different approaches on describing the filmwise condensation were investigated, compared and modified in order to determine a proper heat transfer coefficient for the VPS process - where the heated assembly can be considered as a horizontal plate. For the verification, measurements were done in an experimental soldering oven. The results of the calculations show a proper approximation with the measured temperature data. Finally the results were compared with a solution obtained from complex multiphysics simulation. The results point out, that the application of filmwise condensation model for VPS can be more practical than a complex multi-physics model, from the aspect of calculation error and computation time.
\end{abstract}

Keywords: vapour phase soldering, filmwise condensation, horizontal plate, Nusselt theory; 


\begin{tabular}{|lll|}
\hline Nomenclature & \\
$T$ & temperature, $\mathrm{K}$ & Subscripts: \\
$Q$ & thermal energy, & $b \quad$ body \\
$h$ & heat transfer coefficient, $\mathrm{W} / \mathrm{m}^{2} \cdot \mathrm{K}$ & sat saturation \\
$A$ & body surface, $\mathrm{m}^{2}$ & $F R 4$ Flame-Retardant Class $4, \mathrm{PCB}$ type \\
$t$ & time, $\mathrm{s}$ & $l \quad$ liquid \\
$L$ & characteristic length, $\mathrm{m}$ & $v \quad$ vapour \\
$A$ & surface, $\mathrm{m}^{2}$ & $a m b$ ambient \\
$k$ & thermal conductivity, $\mathrm{W} / \mathrm{m} \cdot \mathrm{K}$ & $R E F$ reference \\
$h l v$ & specific heat of vaporization, $\mathrm{kJ} / \mathrm{kg}$ & $c o r$ corrected form \\
$\rho$ & density, $\mathrm{kg} / \mathrm{m}^{3}$ & $\mathrm{Model}-$ subscripts: \\
$\alpha$ & inclination angle, & \\
$g$ & gravitational constant, $\mathrm{m} / \mathrm{s}^{2}$ & $N L$ Nimmo-Leppert \\
$\mu$ & dynamic viscosity, $\mathrm{kg} / \mathrm{m} \cdot \mathrm{s}$ & $B E$ Bejan \\
$N u$ & Nusselt number, dimensionless & $G G$ Gerstmann-Griffith \\
$R a$ & Rayleigh number, dimensionless & $L E$ Leider \\
$C$ & Specific heat capacity, $\mathrm{J} / \mathrm{kg} \cdot \mathrm{K}$ & $V P S$ Vapour Phase Soldering \\
$\sigma$ & Dimensionless condensation coeff. & \\
\hline
\end{tabular}




\section{Introduction}

Vapour Phase Soldering (VPS, also Condensation Soldering) is a specific heat transfer method for reflow soldering. Reflow soldering is widely used in the electronics manufacturing, where the connections of Printed Circuit Boards (PCBs) and the leads of electronic components are joined with solder alloys. The assembly process is basically depending on reflow soldering. During the process, solder is deposited onto the pad surfaces of the PCB in paste form with stencil printing, and then the components are positioned and placed onto their proper position. Finally the solder joints are formed by melting the alloy and cooling down the whole assembly. The quality of the reflowed solder connection is depending on the thermal experience of the joint itself, so it is important to control and understand heat transfer mechanism of the utilized reflow technology.

VPS technology is mainly used as an alternative of more conventional heat transfer methods, such as infra-red or convection heating; however the demand for VPS is increasing, due to its special approach on heating the assembly. During the process of VPS a heat transfer fluid is heated inside a tank which generates a vapour space in the process zone. The assembly is lowered into the quiescent vapour in the vapour space. Condensation takes place on the colder surfaces of the assembly, and the condensate eventually heats it up [1]. The vapour layer is usually considered to be saturated during the basic application of VPS, however non-saturated vapour blankets can be used for more sophisticated heating. The more expensive types of VPS ovens are able to control pre-heat and cooling during the process, but these solutions use radiation-type heaters and convection-based cooler fans. The most critical part of the thermal treatment (around the liquidus temperature of the solder) is always solved with condensation heating in current VPS ovens.

The technology itself was presented in the seventies [2], then banned due to the extensive amounts of released CFC gases [1]. Later it was improved on many points ever since the introduction of Galden fluid, which is used now as the heat transfer medium [3]. Galden is a perfluoropolyether type polymer fluid, with specific parameters suited not only for the VPS technology, but for different other applications, such as semiconductor cleaning or mechanical lubricating. The literature also points out the universal application of the method in electronics manufacturing [4-7] highlighting compatibility with different solder alloys from special $\mathrm{Sn}-\mathrm{Bi}$ 
based pastes with low melting point $\left(138^{\circ} \mathrm{C}\right)$, to the more conventional SAC305 $(96.5 \% \mathrm{Sn}$, $3 \% \mathrm{Ag}$ and $0.5 \% \mathrm{Cu}$ ) lead-free type of pastes (with a melting point of $217^{\circ} \mathrm{C}$ ). The main advantages of the technology are considered to be the uniform heating of the assembly, and the reduced risk of overheating, due to a fixed boiling point temperature of the fluid. [1] The oxygenfree environment is also important; oxidation-free soldering can be achieved due to the covering continuous film layer of the condensate, which keeps out any gas from the surface of the alloy.

The lack of scientific approach for the description of the heat-transfer mechanism during the process is a serious gap in the current literature; mainly empirical results and simple descriptions exist, which do not go into deeper discussion regarding the heat transfer mechanisms taking place during VPS. A basic description was introduced by Leider [3] declaring a higher heat transfer coefficient than in the case of common, conventional reflow technologies. In a previous investigation [8,9], a multi-physics model was introduced in order to simulate the vapour relations and the temperature of an immersed body, however the method is not practical from industrial application aspects, due to the extensive calculation time. It is important to find a proper and efficient model of the heat transfer to achieve a deeper understanding of the whole process, and achieve better temperature control - ultimately - better quality of the formed solder joints.

\section{Filmwise condensation theory}

The heating of the PCB (the assembly to be soldered) can be modeled with the theory of condensation. Condensation occurs when the surface of the PCB is in contact with the vapour atmosphere, where the vapour temperature is higher than the temperature of the assembly. The molecules in contact with the cooler surface condense, meanwhile forming a continuous film layer. The phenomenon can be considered as the classical case of filmwise condensation. During the VPS process the PCB is immersed into the vapour in a horizontal orientation. The top side of the PCB can be considered as an upward facing plate, with free edges, so the condensed liquid is able to spill down at the edges, back to the reservoir at the bottom of the tank. Basically the steady state thickness of the film is settled with the balance of the condensation rate on the surface and the downward flow rate along the edges. Condensation also occurs on the bottom side, forming a wavy surface of fluid film, according to the Rayleigh-Taylor instability [10, 11]. The generated condensate drips down intermittently from the wavy film. 


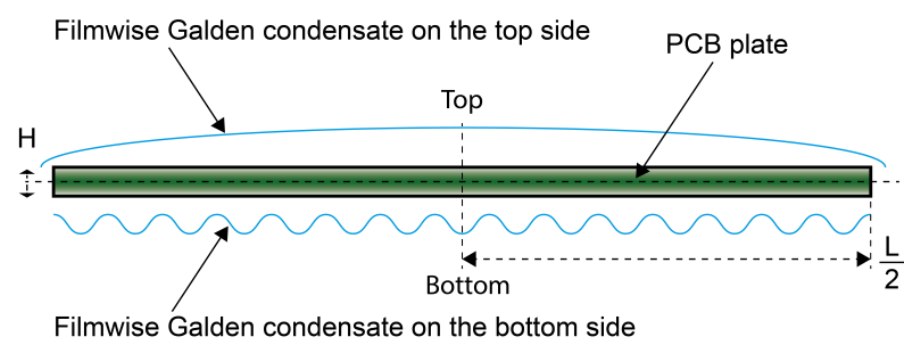

Fig. 1. Condensation of Galden on the PCB

Consider a 2D geometry, shown on Figure 1, which is a cross section of the PCB "plate" with an edge length of $\mathrm{L}$ and a plate height of $\mathrm{H}$, where $\mathrm{L}>>\mathrm{H}$. The condensate is assumed to have laminar flow within the film layer along the L length, where the thickness of the condensate is the highest at the center of the plate. For a simplified approach on VPS we also assume the following conditions:

- there is conductive heat transfer between the solid body and the film,

- there is no slip condition at the solid-liquid boundary,

- there is uniform solid body temperature,

- there is saturated unperturbed-quiescent vapour (which is already set to a steady state of saturation, described in [12]),

- there is a lack of interfacial resistance to heat transfer at the liquid-vapor interface,

- there is a lack of momentum effect in the condensate (no downward drag caused by the vapour),

- the consumed vapour is always regenerated by the boiling Galden in the vapour space,

- the dynamic material properties are controlled in function of temperature.

A simple description can be used to describe the heating of the PCB. The heating (or cooling) of a body can be described with the law of Newton:

$$
\frac{d Q_{b}}{d t}=h \cdot A \cdot\left(T_{s a t}-T_{b}\right)
$$

where $\left(Q_{\mathrm{b}}\right)$ is the thermal energy of the body [J], $(h)$ is the heat transfer coefficient across the boundary of the filmwise condensate and the horizontal FR4 plate surfaces $\left[\mathrm{W} / \mathrm{m}^{2} \mathrm{~K}\right],(A)$ is the surface whereon the condensation occurs $\left[\mathrm{m}^{2}\right],\left(T_{b}\right)$ is the temperature of the body and $\left(T_{s a t}\right)$ is the 
temperature of the vapour $[\mathrm{K}],(t)$ is the time $[\mathrm{s}]$. The increase of the body temperature can be calculated with:

$$
\frac{d T_{b}}{d t}=\frac{Q_{b}}{C_{b} \cdot m_{b}}
$$

where $\left(\mathrm{C}_{\mathrm{b}}\right)$ is the specific heat of the body (standard FR4 PCB material in this case) $[\mathrm{J} / \mathrm{kg} \cdot \mathrm{K}]$, $\left(m_{b}\right)$ is the mass of the body $[\mathrm{kg}]$.

Nusselt [13] was the first who described the heat transfer of filmwise condensation on a surface of a vertical wall. After calculating the force balances, the local flow rate of the condensate and the film thickness, his model gives the following formula for the heat transfer coefficient:

$\overline{h_{L}}=\frac{N u \cdot k_{l}}{L}=\frac{k_{l}}{L} \cdot 0.943 \cdot\left(\frac{h_{l v} \cdot \rho_{l} \cdot\left(\rho_{l}-\rho_{v}\right) \cdot g \cdot \sin \alpha \cdot L^{3}}{\left(T_{s a t}-T_{b}\right) \cdot \mu_{l} \cdot k_{l}}\right)^{\frac{1}{4}}$

where $(L)$ is the $z$ dimensional length of the film condensed on a vertical wall $[\mathrm{m}],\left(h_{L}\right)$ is the Laveraged heat transfer coefficient $\left[\mathrm{W} / \mathrm{m}^{2} \cdot \mathrm{K}\right],(\mathrm{Nu})$ is the L-averaged Nusselt number $\left(k_{l}\right)$ is the thermal conductivity $[\mathrm{W} / \mathrm{m} \cdot \mathrm{K}],\left(h_{l v}\right)$ is the latent heat of vaporization $[\mathrm{kJ} / \mathrm{kg}],\left(\rho_{l}\right)$ is the density of the liquid $\left[\mathrm{kg} / \mathrm{m}^{3}\right],\left(\rho_{v}\right)$ is the density of the vapour $\left[\mathrm{kg} / \mathrm{m}^{3}\right],(g)$ is the gravitational constant $\left[\mathrm{m} / \mathrm{s}^{2}\right],\left(T_{S A T}\right)$ is the temperature of the vapour $[\mathrm{K}],\left(T_{b}\right)$ is the temperature of the body $[\mathrm{K}]$, and $\left(\mu_{l}\right)$ is the dynamic viscosity $[\mathrm{kg} / \mathrm{m} \cdot \mathrm{s}]$. The model has an implemented correction to handle the inclination of the surface $(\sin \alpha)$ [14], meanwhile predicting zero heat transfer when the surface becomes horizontal and the angle becomes zero - thus this model is not applicable on the case of VPS in its present form.

During the years the Nusselt-model had been refined for horizontal cases according to experimental-analytical data. Popov [15] was the first to study the condensation for horizontal surfaces; however the first proper model for heat transfer prediction on the upper side of a horizontal plate was introduced by Nimmo and Leppert [16, 17]. They assumed that the condensate flow on the top of a horizontal plate depends on the hydrostatic pressure gradient caused by the changes in the film thickness from the center to the edge of the plate. Their model incorporates a correction on the one-fourth exponent of Nusselt to one-fifth, also highlighted by Chiou and Chang [18] and Bejan [19] for horizontal cases. Modifications on their model by other 
researchers [17] predicted slightly different solutions, but there was no significant improvement on the original, from the aspect of precise approximation. From the Nimmo-Leppert model the following heat transfer coefficient $\left(\mathrm{h}_{\mathrm{L}_{-} \mathrm{NL}}\right)$ can be defined for the top side of the plate:

$\overline{h_{L_{-} N L}}=\frac{k_{l}}{L} \cdot\left(\frac{h_{l v} \cdot \rho_{l}^{2} \cdot g \cdot L^{3}}{\left(T_{s a t}-T_{b}\right) \cdot \mu_{l} \cdot k_{l}}\right)^{\frac{1}{5}}$

Based on previous results [20] of extensive investigations, Bejan added [19] the condition of zero film thickness at the top edge of the plate, where the flow rate reaches its highest finite value. His model incorporates the one-fifth exponent and a correction (5) introduced by Roshenow. Roshenow showed [17, 21] that the latent heat of vaporization should be refined if the temperature of the filmwise condensate is allowed to have a nonlinear distribution within the film itself. The correction is derived from the following formula:

$h_{l v}{ }^{\prime}=h_{l v}+0.68 \cdot C \cdot\left(T_{v}-T_{b}\right)$

where $\left(h_{l v}\right)$ is the corrected form of the latent heat, $(C)$ is the specific heat of the condensate (the Galden itself). According to the calculated formula of Bejan, the heat transfer coefficient $\left(h_{L_{-} B E}\right)$ for the top side of the plate is:

$\overline{h_{L_{-} B E}}=1.079 \cdot \frac{k_{l}}{L} \cdot\left(\frac{h_{l v}{ }^{\prime} \cdot \rho_{l} \cdot\left(\rho_{l}-\rho_{v}\right) \cdot g \cdot L^{3}}{\left(T_{s a t}-T_{b}\right) \cdot \mu_{l} \cdot k_{l}}\right)^{\frac{1}{5}}$

The effect of condensing film on the bottom side of a horizontal plate requires a different approach and was investigated by Gerstmann and Griffith [17, 22]. Their model is based on the aforementioned Taylor instability, and can be used as a complementary solution - in addition to the calculations on the top side. Their obtained heat transfer coefficient can be defined from the calculated Nusselt number $\left(N u_{G G}\right)$ :

$$
N u_{G G}=\frac{0.90 \cdot R a^{\frac{1}{6}}}{\left(1+1.1 \cdot R a^{-\frac{1}{6}}\right)}
$$

where $(R a)$ is the Rayleigh-number. It is calculated as: 
$R a=\frac{g \cdot \rho_{l} \cdot\left(\rho_{l}-\rho_{v}\right) \cdot h_{l v}}{\mu_{l} \cdot \Delta T \cdot k_{l}} \cdot\left(\frac{\sigma}{g \cdot\left(\rho_{l}-\rho_{v}\right)}\right)$

where $(\sigma)$ is the dimensionless condensation coefficient. Finally the heat transfer coefficient for the bottom side can be calculated as:

$\overline{h_{L_{-} G G}}=N u_{G G} \cdot k_{l} /\left(\frac{\sigma}{g \cdot\left(\rho_{l}-\rho_{v}\right)}\right)^{\frac{1}{2}}$

This form was originally intended to be used in a case when a slight inclination of the body is observable. During verification, this solution has approximated our results with the least error, so it was applied later for the given case of VPS.

Along the different descriptions for top and bottom sides of a horizontal plate, Leider published [3] a formula of an overall heat transfer coefficient for the case of VPS originated from Nusselt; however his description lacked a thorough deduction. Also his approximation did not incorporate any difference between different sides of the PCB, and also lacked the previously introduced corrections. His approach is the only VPS related description available in the literature. It is written in the following form:

$\overline{h_{L_{-} L E}}=0.943 \cdot\left(\frac{h_{l v} \cdot \rho_{l}{ }^{2} \cdot k_{l}^{3}}{\left(T_{s a t}-T_{b}\right) \cdot \mu_{l} \cdot L}\right)^{\frac{1}{4}}$

\section{Applied methods and system parameters}

The thermal energy of the heated PCB plate can be calculated with (1), assuming the PCB has two different surfaces (top, bottom) with two different heat transfer coefficients, so our proposed explicit filmwise model calculates heat transfer simultaneously on both surfaces (where each surface is equally $(A))$. The heat transfer from the horizontal edge surfaces can be neglected due to the plate geometry ratios discussed before. For the calculations MATLAB software was used.

To verify the calculations, a measurement was carried out in an experimental VPS setup which was described in our previous work in details [23]. Figure 2 shows the setup, where the tank is illustrated with semi-transparent wall for better overview. The vapour space of the setup contains saturated vapour of Galden HT170. The fluid was chosen to achieve faster experimental validation results; the cycles of the setup are much shorter in this case than in the case of Galden 
for lead-free soldering at $230^{\circ} \mathrm{C}$. HT170 is also relevant from the aspect of soldering with low melting point solder alloys, such as Sn-Bi type pastes. With proper parameter setting, HT170 and the more common LS230 liquid (relevant from conventional lead free temperatures) are commutable from the aspect of our method.

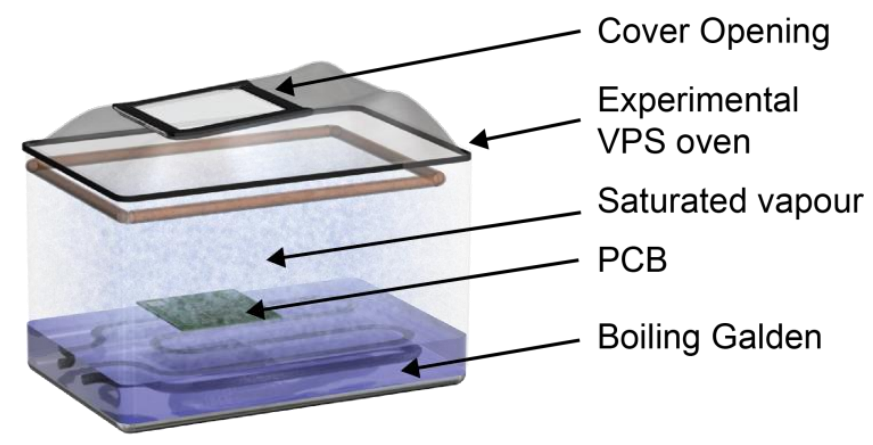

Fig. 2. Experimental VPS setup with a PCB immersed into saturated vapour

The vapour blanket was achieved with $550 \mathrm{~W}$ heating power. During the investigations a plain FR4 board (with $80 \times 80 \times 1.6 \mathrm{~mm}^{3}$ ) was immersed into the saturated vapour. The temperature is measured with K-Type thermocouples with the precision of $\left( \pm 0.5^{\circ} \mathrm{C}\right)$. The thermocouples were positioned in small bores on the PCB in five positions, and then were fixed with Loctite 3621 SMD adhesive. The temperature curves were then averaged to get a mean temperature of the board itself. The ambient $\left(T_{a m b \_b}\right)$ initial temperature of the plate is $313 \mathrm{~K}\left(40{ }^{\circ} \mathrm{C}\right)$ due to a preheating effect, which occurs when the PCB is positioned above the opening of the VPS tank. The PCB is immersed into the vapour trough the opening with a thin copper wire fixed on the four corners of the PCB in small vias, minimizing additional thermal capacitances and any perturbing effect regarding the filmwise condensation.

Table 2 shows the parameters which were used during the calculations. The parameters of the Galden liquid are obtained from catalogue data [24].

Table 2. Parameters of the applied materials

\begin{tabular}{|l|l|l|l|l|l|}
\hline $\begin{array}{l}\text { Material } \\
\text { Parameter }\end{array}$ & $\begin{array}{l}\text { Density } \\
{\left[\mathrm{kg} / \mathrm{m}^{3}\right]}\end{array}$ & $\begin{array}{l}\text { Specific heat } \\
{[\mathrm{J} / \mathrm{kg} \cdot \mathrm{K}]}\end{array}$ & $\begin{array}{l}\text { Thermal cond. } \\
{[\mathrm{W} / \mathrm{m} \cdot \mathrm{K}]}\end{array}$ & $\begin{array}{l}\text { Latent heat } \\
{[\mathrm{J} / \mathrm{kg} \cdot \mathrm{K}]}\end{array}$ & $\begin{array}{l}\text { Saturation temp. } \\
{\left[{ }^{\circ} \mathrm{C}\right]}\end{array}$ \\
\hline FR4 & 1850 & 600 & 0.25 & - & - \\
\hline HT170 & $*$ & 971 & 0.065 & 66988 & 170 \\
\hline
\end{tabular}


The variable thermophisycal properities of the Galden HT170 (density, as noted (*) in Table 2, and dynamic viscosity) were obtained from the catalogue too [24]. The reciprocal plot of dynamic viscosity characteristic (calculated from kinematic viscosity) has a slight nonlinearity as shown on Fig 3.

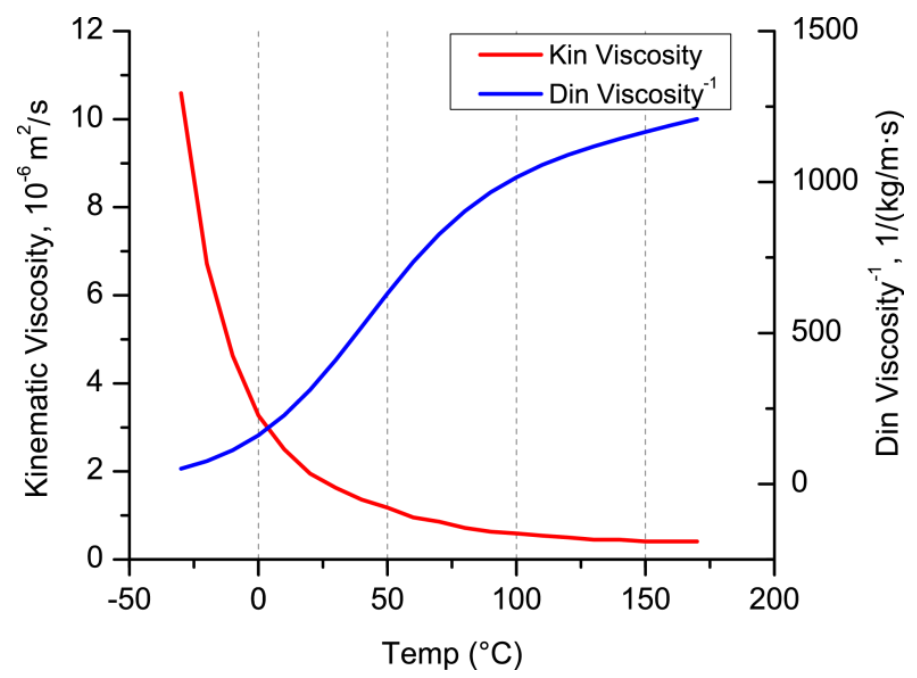

Fig. 3. Dynamic parameters of Galden HT170

To calculate the heating, separate cases were considered, to differentiate the heat transfer calculation variations. For the top surface the Nimmo-Leppert and Bejan models were applied as approximating model; for the bottom, the Gerstmann-Griffith model was applied. The Leider model was applied for both surfaces in the same time due to its general form. The different cases are shown on Table 1.

Table 1. Different cases for calculations

\begin{tabular}{|c|c|c|}
\cline { 2 - 3 } \multicolumn{1}{c|}{} & \multicolumn{2}{c|}{ Applied Model on the Given Side } \\
\hline CASES & TOP & BOTTOM \\
\hline A & Nimmo-Leppert & Gerstmann-Griffith \\
\hline B & Bejan & Gerstmann-Griffith \\
\hline C & Leider & Leider \\
\hline
\end{tabular}

The calculations are compared with the measured data, to find the best approximation, with the least error. First the calculations were initiated with the basic, literature form of the models. To improve the initial results additional corrections were applied to the original correlations. Aside the Roshenow correction and the one-fifth exponent, we have introduced an additional empirical 
correction, which was found by Drew $[17,24]$. He pointed out, that the physical properties and dynamic material parameters should be evaluated at a reference temperature calculated from:

$T_{R E F}=T_{S A T}-K \cdot\left(T_{S A T}-T_{b}\right)$

where $(K)$ is a constant, which was defined to be 0,75 according to Drew. Drew suggested his correction for the cases where $1 / \mu_{1}$ can be considered linear. The actual reciprocal plot of the dynamic viscosity (according to Figure 3.) is deviating with an average of $\sim 105[1 /(\mathrm{kg} / \mathrm{m} \cdot \mathrm{s})](\sim 10.5 \% \mathrm{avg}$. error $)$ from the linear approximation, but this imprecision will be neglected during the calculations, and in the relevant temperature range $\left(40-170{ }^{\circ} \mathrm{C}\right)$ the nonlinearity will be roughly approximated with a linear solution. Further correction of the Drew factor should be investigated in the future works. First the corrections were investigated separately to find if there is improvement upon the original forms. Then it was found that we were able to use a combined correction on the original models. For the Nimmo-Leppert model, we have combined both the Roshenow and Drew corrections; for the Bejan model, we have applied the Drew correction upon the already incorporated Roshenow correction on the latent heat; for the bottom (Gerstmann-Griffith model) we have applied both Roshenow and Drew corrections. For the Leider model both Roshenow and Drew corrections were added to obtain overall improvement, and the 1/5th exponent was also introduced according to the horizontal positioning.

\section{Results}

The calculations gave the following results. Figure 4 shows the results with the original models, Case A and B gave the best result according to the measured data, but all cases have a considerable deviation. Generally the results with these combined corrections $(C O R)$ have considerably improved, showing a proper approximation (Figure 4) of the measurement.

For the applied Gerstmann-Griffith model during calculation Cases A and B we used a condensation coefficient of 0.8 which was found to give the best approximation. The literature aims this value at 1.0 for condensation of a metal vapor and less than 1.0 (most probably around 0.4) for water steam [17]. Compared to water vapour and according to the Galden material parameters, our approximation should be proper for Galden vapour. For the Leider model (Case C) none of the corrections resulted in a better approximation, however the physical content of 
them are relevant. This also points out that the Leider model is the least reliable due to its basic generalization of the Nusselt theory.

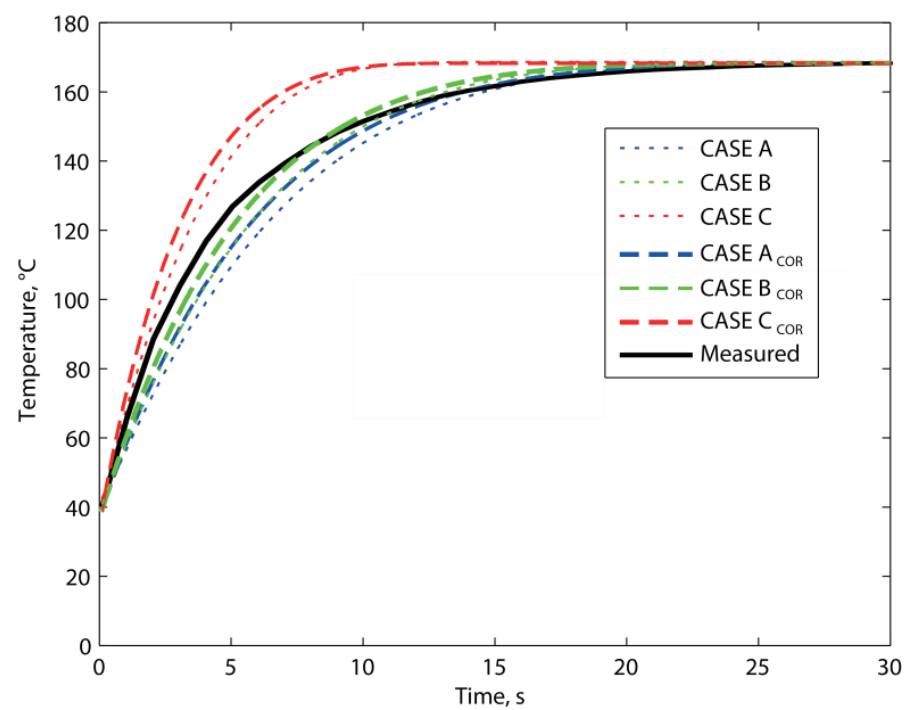

Fig. 4. Calculation-measurement comparison with original models and with combined corrections (COR).

An error sweep on the corrected models shows the actual difference between the measured and the calculated values along the heating period. The error profiles show that the main part of the average error comes from the deviation at the ramp-up period - this is also observable on Figure 4. Also the applied combined corrections render a considerable improvement on the calculations. The overall best approximation (Case B COR) has a trade-off, while it has the lowest deviation at the ramp-up period while also it has a slower settling at the saturation temperature. The Leider model (Case C) again shows a totally different behavior with an overshoot, and the least precise approximation. 


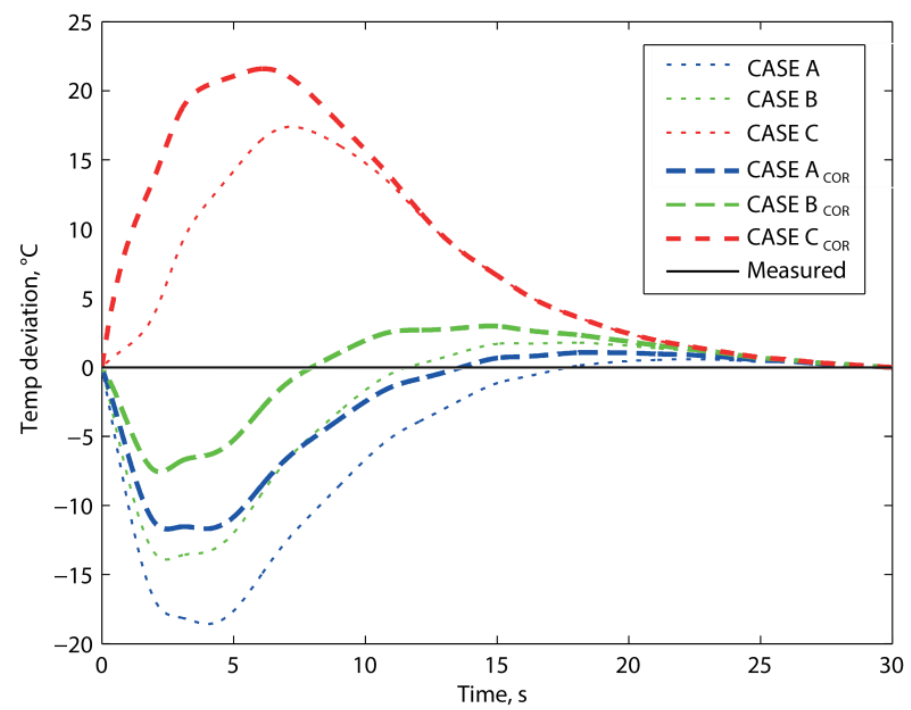

Fig. 5. Difference sweep of calculations and measurement

Figure 6 shows the direct comparison of the errors. According to the literature, $10 \%$ overall error is widely accepted in such modeling cases. The averaged difference between the measured and the calculated data shows that Case B approximates measured data with the least maximum and least overall error. With Case $\mathrm{B}_{\mathrm{COR}}$, it is possible to approximate the heating of a PCB with $4,46 \%$ maximum and $1,38 \%$ overall relative error. This magnitude of error is also comparable with the imprecision of the actual measuring sensors.

It can be said that the corrected form of Case B significantly reduces the overall deviation compared to the VPS-specific Leider description (Case C).

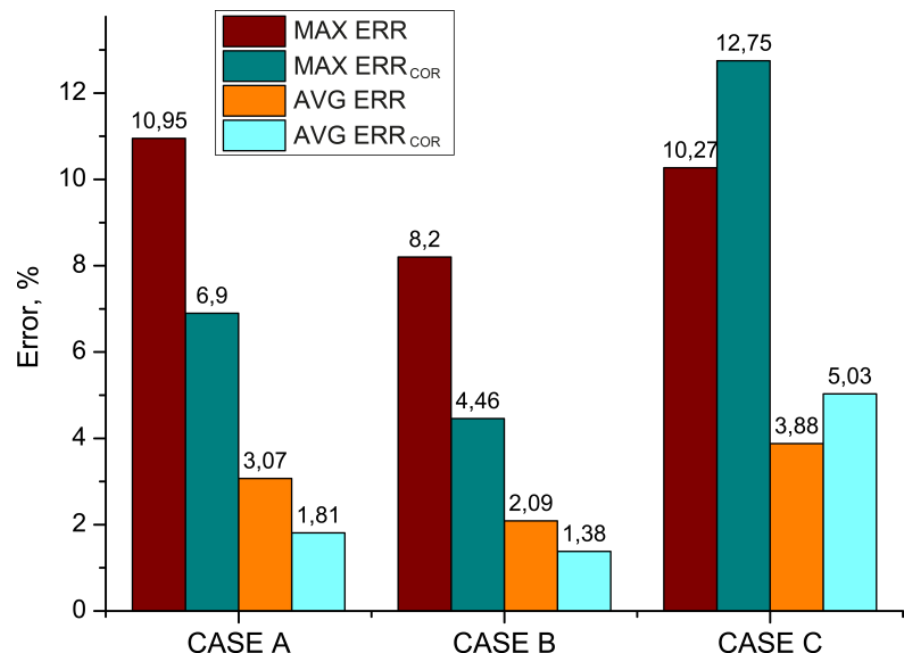

Fig. 6. Error comparison; maximum and average deviations from measurement 
The calculated heat transfer coefficients with applied combined corrections are shown on Figure 7. From the previous results, it was found that above $20 \mathrm{~s}$, the temperature difference between the vapour and the board becomes significantly low; thus the calculation of the heat transfer coefficient starts tending to infinity. However this effect in the results of calculations is negligible, while the calculated temperature has almost reached its saturation. (The temperature difference is $\sim 0.5{ }^{\circ} \mathrm{C}$ at that time point.) The most relevant dynamic heat transfer coefficient (Case $\mathrm{B}_{\mathrm{COR}}$ ) can be approximated between 310 and $770 \mathrm{~W} / \mathrm{m}^{2} \mathrm{~K}$. During Case $\mathrm{C}$ the deviation to infinity sets earlier, showing the unreliability of the model.

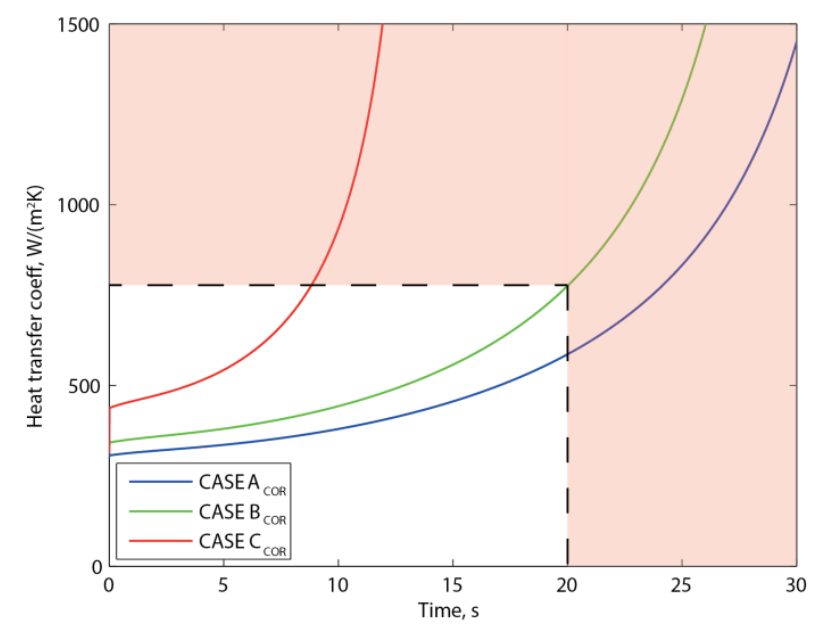

Fig. 7. Relevant window of calculated heat transfer coefficients

According to our findings, we have defined the following approximate heat transfer coefficient for the general case of VPS in the case of a two sided PCB, derived from Case B COR:

$\overline{h_{L_{-} V P S}}=1.079 \cdot \frac{k_{l}}{L} \cdot\left(\frac{h_{l v}^{\prime} \cdot \rho_{l}^{\prime}\left(T_{R E F}\right) \cdot\left(\rho_{l}^{\prime}\left(T_{R E F}\right)-\rho_{v}\right) \cdot g \cdot L^{3}}{\left(T_{s a t}-T_{b}\right) \cdot \mu_{l}^{\prime}\left(T_{R E F}\right) \cdot k_{l}}\right)^{\frac{1}{5}}+\left(\frac{0.90 \cdot k_{l} \cdot\left(R a^{\prime}\right)^{\frac{1}{6}} \cdot \sqrt{g \cdot\left(\rho_{l}^{\prime}\left(T_{R E F}\right)-\rho_{v}\right)}}{\left(1+1.1 \cdot\left(R a^{\prime}\right)^{-\frac{1}{6}}\right) \cdot \sqrt{\sigma}}\right)$

where the corrected values are denoted with (') according to the aforementioned modifications. $\left(\rho_{l}^{\prime}\right)$ and $\left(\mu_{l}^{\prime}\right)$ are calculated in function of $\left(T_{R E F}\right)$ according to Drew. $\left(R a^{\prime}\right)$ incorporates both the Drew and Roshenow corrections: 


$$
R a^{\prime}=\frac{g \cdot \rho_{l}^{\prime}\left(T_{R E F}\right) \cdot\left(\rho_{l}^{\prime}\left(T_{R E F}\right)-\rho_{v}\right) \cdot h_{l v}}{\mu_{l}^{\prime}\left(T_{R E F}\right) \cdot \Delta T \cdot k_{l}} \cdot\left(\frac{0.8}{g \cdot\left(\rho_{l}^{\prime}\left(T_{R E F}\right)-\rho_{v}\right)}\right)
$$

The obtained heat transfer coefficient (12) should be applied in (1), where $(A)$ surface is the surface of a single side (equal on both top and bottom sides of the PCB).

The accuracy and computing time of our simplified filmwise heat transfer description for the VPS process was compared with a more complex multi-physics approach on the problem based on our previous work. The complex VPS process model described in $[8,9]$ calculates the dynamic vapour and temperature space in the VPS tank during the soldering process, with applied combined transport mechanisms including heat transport by heat conduction; mass transport by diffusion in the fluids and phase change during the evaporation and the condensation of the Galden liquid; and energy transport caused by mass transport. The model also uses a special dew point calculation which was developed for Galden liquid by our experiments. The comparison of the results obtained from the two models is presented on Figure 8.

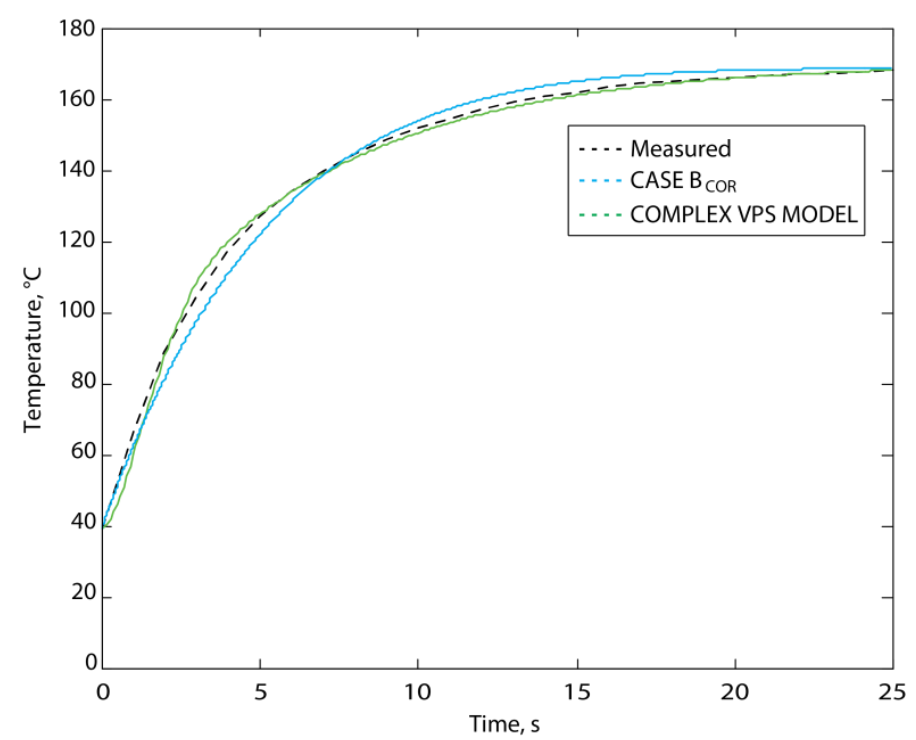

Fig. 8. Comparison of measured data, the filmwise condensation model and the complex multiphysics model for VPS

The results show, that the multi-physics VPS process model has the best approximation. Its precision can be accounted to the focus on the dew point, and also a calculation of the consumed vapour around the board. On the other hand the simple model approximates the result in the order of some seconds, while the multi-physics VPS process calculates its result in the order of 6-8 
hours (using the same hardware configuration). The simple, explicit filmwise VPS model offers a better practical solution in those cases, where a heating profile should be obtained in seconds. (For example in industrial applications where the profile setting interface of a VPS oven should give an intermediate feedback for an operator or an engineer.)

\section{Conclusion}

The paper presents an explicit modeling method where the heating of a PCB is simulated with heat transfer coefficients obtained from filmwise condensation theory. In our approach we combined the top and the bottom sides of a horizontal plate (the PCB itself) to obtain an overall heat transfer coefficient for the VPS process. Refinements were applied on the models in the form of corrections. In the end a combined and corrected solution gave the best result (with a relevant heat transfer coefficient between $\sim 310-770\left[\mathrm{~W} / \mathrm{m}^{2} \mathrm{~K}\right]$ ), approximating measurement data with $\sim 1,38 \%$ overall error. This is an important improvement on the suggested VPS model defined by the literature. Our novel and simple heat transfer model for VPS was compared with a more complex, multi-physics model introduced previously. Both the complex model and the simple model give acceptable prediction of the heat transfer on the PCB. Also the simple filmwise model offered a tolerable trade-off between calculation time and calculation precision enabling it as a future consideration for practical applications in the manufacturing industry, where a proper profile prediction should be obtained in seconds. Future plans involve heat transfer coefficient refinements for the cases, where the vapour is not in its saturated state, to approximate the effect of thermal treatments in more sophisticated VPS ovens.

\section{Acknowledgement}

This paper was supported by the János Bolyai Research Scholarship of the Hungarian Academy of Sciences.

\section{References}

[1] H. Leicht, A. Thumm, Today's Vapor Phase Soldering - An Optimized Reflow Technology for Lead Free Soldering, Proceedings of the Surface Mount Technology Association Int. Conf., USA, 2008, p. 45. 
[2] R.C. Pfahl, H.H. Ammann, Method for Soldering, Fusing or Bracing, 1975, US Patent $3,866,307$

[3] W. Leider, Dampfphasenlöten - Grundlagen und praktische Anwendung, first ed., Eugen G. Leuze Verlag, Bad Saulgau, Germany, 2002, pp. 31-39.

[4] O. Krammer, T. Garami, Investigating the Mechanical Strength of Vapor Phase Soldered Chip Components Joints, Proceedings of IEEE Int. Symposium for Design and Technology in Electronic Packaging at Pitesti, Romania, 2010, pp. 103-106.

[5] I. Plotog, T. Cueu, B. Mihaileseu, G. Varzaru, P. Svasta, I. Busu, PCBs with Different Core Materials Assembling in Vapor Phase Soldering Technology, Proceedings of IEEE ISETC $9^{\text {th }}$ International Symposium on Electronics and Telecommunications, Romania, 2010, pp. 421424.

[6] A. Duck, C. Zabel, Vapour Phase Reflow - Profiling for Lead Free Alloys..., Proceedings of International Conference on Soldering and Reliability, Toronto, Canada, 2010, P. No. 2

[7] N. D. Codreanu, P. Svasta, I. Plotog, I. Oancea, G. Vărzaru, T. C. Cucu, Lead-Free Electronic System integrated in a Vapour Phase Soldering Equipment Prototype, Proceedings of $32^{\text {nd }}$ International Spring Seminar on Electronics Technology, Brno, Czech Republic, 2009, pp. 15.

[8] B. Illés, A. Géczy, Multi-Physics Modelling of a Vapour Phase Soldering (VPS) System, Applied Thermal Engineering 48 (2) (2012) 54-62.

[9] B. Illés, A. Géczy, Investigating the dynamic changes of the vapour concentration in a vapour phase soldering oven by simplified condensation modelling, Applied Thermal Engineering, In Press, Accepted manuscript, http://dx.doi.org/10.1016/j.applthermaleng.2013.05.008

[10] G.I. Taylor, The instability of liquid surfaces when accelerated in a direction perpendicular the their planes, International Proceedings of Royal Society A 201 (1950) 192196.

[11] S. M. Som, J. T. Kimball, J. C. Hermanson, J. S. Allen, Stability and heat transfer characteristics of unsteady condensing and evaporating films, International Journal of Heat and Mass Transfer 50 (2007) 1927-1937. 
[12] A. Géczy, B. Illés, Z. Péter, Z. Illyefalvi-Vitéz, Characterization of Vapour Phase Soldering Process Zone with Pressure Measurements, Soldering \& Surface Mount Technology, 25 (2) (2013) 99-106.

[13] W. Nusselt, Die Oberflachenkondensation der Wasserdampfes, Zeitung des Vereins Deutscher Ingenieure 60 (1916) 541-569.

[14] J.G. Collier, J.R. Thome, Convective Boiling and Condensation, third ed., Clarendon Press, Oxford, 1994, pp. 484.

[15] V. D. Popov, Heat Transfer During Vapor Condensation on Horizontal Surfaces. Trudy

Kiev. Teknol. Inst. Pishch, Prom. 11 (1951) pp. 87-97

[16] B. G. Nimmo, G. Leppert, Laminar Film Condensation on a Finite Horizontal Surface, Proceedings of 4th International Heat Transfer Conference, France, Paris, 1970, 402-403.

[17] P. J. Marto, W. M. Rohsenow, J. P. Hartnett, Young, I. Cho, first ed., Handbook of Heat Transfer, McGraw-Hill, New York, 1998, 14.1-14.27.

[18] J.S.Chiou, T.B. Chang, Laminar film condensation on a horizontal disk, Heat and Mass Transfer 29 (1994) 141-144.

[19] A. Bejan, Film condensation on an upward facing plate with free edges, International Journal of Heat and Mass Transfer 34 (1991) 582-587.

[20] S. Kimura, A. Bejan and I. Pop Natural convection near a cold plate facing upward in a porous medium, Journal of Heat Transfer 107 (1985) 819-825

[21] W. M. Rohsenow, Heat Transfer and Temperature Distribution in Laminar Film Condensation, Transactions of ASME 78 (1956) 1645-1648.

[22] J. Gerstmann, P. Griffith, Laminar film condensation on the underside of horizontal and inclined surfaces, International Journal of Heat and Mass Transfer 10 (1967) 541-569.

[23] A. Geczy, Z. Illyefalvi-Vitez, P. Szoke, Investigations on Vapor Phase Soldering Process in an Experimental Soldering Station, Micro and Nanosystems 2 (2011) 170-177.

[24] Datasheet of Galden HT170, http://www.daitokutech.com/products/galden/data/HT170.pdf, (accessed: 2013.04.10.)

[25] T. B. Drew (personal communication) in W. H. McAdams, Heat Transmission, third ed., McGraw-Hill, New York, 1954, p. 330, 